\title{
Fixed point theorems and iterative approximations for monotone nonexpansive mappings in ordered Banach spaces
}

Yisheng Song ${ }^{1}$, Poom Kumam² ${ }^{2 *}$ and Yeol Je Cho ${ }^{2,3^{*}}$

\section{"Correspondence:}

poom.kum@kmutt.ac.th;

yjcho@gnu.ac.kr

${ }^{2}$ Department of Mathematics, King

Mongkut's University of Technology

Thonburi, 120 Pracha-Uthnit Road,

Bang Mod, Thung Khru, Bangkok,

10140, Thailand

${ }^{3}$ Department of Mathematics

Education and the RINS,

Gyeongsang National University,

Jinju, 660-701, Korea

Full list of author information is

available at the end of the article

\begin{abstract}
In this paper, we prove some existence theorems of fixed points of a monotone nonexpansive mapping $T$ in a Banach space $E$ with the partial order ' $\leq$ ', where a such mapping may be discontinuous. In particular, in finite dimensional spaces, such a mapping $T$ has a fixed point in $E$ if and only if the sequence $\left\{T^{n} 0\right\}$ is bounded in $E$. In order to find a fixed point of such a mapping $T$, we prove the weak convergence of the Mann iteration scheme under the condition $\sum_{n=1}^{\infty} \beta_{n}\left(1-\beta_{n}\right)=\infty$, which entails $\beta_{n}=\frac{1}{n+1}$ as a special case.
\end{abstract}

MSC: 47H06; 47J05; 47J25; 47H10; 47H17; 49J40; 47H04; 65J15

Keywords: ordered Banach space; fixed point; monotone nonexpansive mapping; $\lambda$-hybrid mapping; Mann iterative scheme

\section{Introduction}

Let $T$ be a mapping with domain $D(T)$ and range $R(T)$ in a Banach space $E$. Then $T$ is called nonexpansive if

$$
\|T x-T y\| \leq\|x-y\|
$$

for all $x, y \in D(T)$. The fixed point set of $T$ is denoted by $F(T):=\{x \in K ; T x=x\}$.

In 2010, Aoyama et al. [1] introduced a class of $\lambda$-hybrid mappings, that is, a mapping $T$ is called a $\lambda$-hybrid mapping in Hilbert space $H$ if

$$
\|T x-T y\|^{2} \leq\|x-y\|^{2}+2(1-\lambda)\langle x-T x, y-T y\rangle
$$

for all $x, y \in D(T)$. They showed a fixed point theorem and an ergodic theorem for such a mapping. Clearly, a nonexpansive mapping is a 1-hybrid mapping. In 2011, Aoyama and Kohsaka [2] also introduced the concept of $\alpha$-nonexpansive mapping, that is, a mapping $T$ is called $\alpha$-nonexpansive if $\alpha<1$ and

$$
\|T x-T y\|^{2} \leq \alpha\|T x-y\|+\alpha\|T y-x\|+(1-2 \alpha)\|x-y\|
$$

for all $x, y \in D(T)$. Obviously, a nonexpansive mapping is 0 -nonexpansive and a $\lambda$-hybrid mapping is $\frac{1-\lambda}{2-\lambda}$-nonexpansive if $\lambda<2$ in a Hilbert space $H$ (for more details, see [2]).

(c) 2016 Song et al. This article is distributed under the terms of the Creative Commons Attribution 4.0 International License (http://creativecommons.org/licenses/by/4.0/), which permits unrestricted use, distribution, and reproduction in any medium, provided you give appropriate credit to the original author(s) and the source, provide a link to the Creative Commons license, and indicate if changes were made. 
The following classical result for nonexpansive mappings was showed to still hold for $\alpha$-nonexpansive mappings in a uniformly convex Banach space $E$.

Theorem 1.1 ([2]) Let $C$ be a nonempty and closed convex subset of uniformly convex Banach space $E$ and $T: C \rightarrow C$ be an $\alpha$-nonexpansive mapping. Then $F(T) \neq \emptyset$ if and only if $\left\{T^{n} x\right\}$ is bounded for some $x \in C$.

Very recently, Bachar and Khamsi [3] introduced the concept of a monotone nonexpansive mapping in a Banach space $E$ endowed with the partial order ' $\leq$ ' and investigated common approximate fixed points of monotone nonexpansive semigroups. A mapping $T: D(T) \rightarrow R(T)$ is called monotone nonexpansive if $T$ is monotone ( $T x \leq T y$ whenever $x \leq y)$ and

$$
\|T x-T y\| \leq\|x-y\|
$$

for all $x, y \in D(T)$ with $x \leq y$. Clearly, a monotone nonexpansive mapping may be discontinuous.

In this paper, we show the following existence theorem of fixed points for a monotone nonexpansive mapping $T$.

Theorem 1.2 Let $K$ be a nonempty and closed convex subset of a uniformly convex Banach space $(E, \leq)$ and $T: K \rightarrow K$ be a monotone nonexpansive mapping. Assume that there exists $x \in K$ such that $x \leq T x$ (or $T x \leq x)$ and the sequence $\left\{T^{n} x\right\}$ is bounded. Then $F(T) \neq \emptyset$ and $x \leq y^{*}\left(\right.$ or $\left.y^{*} \leq x\right)$ for some $y^{*} \in F(T)$.

In order to finding a fixed point of a nonexpansive mapping $T$, Mann [4] introduced the following iteration scheme which is referred to as the Mann iteration: for any $x_{1} \in$ $D(T)$,

$$
x_{n+1}=\beta_{n} x_{n}+\left(1-\beta_{n}\right) T x_{n}
$$

for each $n \geq 1$, where $\beta_{n} \in[0,1]$ is a sequence with some conditions. Subsequently, many mathematical workers have been investigated the convergence of the Mann iteration and its modified version for nonexpansive mappings and pseudo-contractions. For example, see [5-14]. However, there are not many convergence theorems of such an iteration in an ordered Banach space $(E, \leq)$. Recently, Dehaish and Khamsi [15] obtained the weak convergence of the Mann iteration for a monotone nonexpansive mapping provided $\alpha_{n} \in[a, b] \subset(0,1)$. But their results do not entail $\beta_{n}=\frac{1}{n+1}$.

Motivated by the above results, we consider the weak convergence of the Mann iteration scheme for a monotone nonexpansive mapping $T$ under the condition

$$
\sum_{n=1}^{\infty} \beta_{n}\left(1-\beta_{n}\right)=\infty
$$

which contain $\beta_{n}=\frac{1}{n+1}$ as a special case. 


\section{Preliminaries and basic results}

Let $P$ be a closed convex cone of a real Banach space $E$. A partial order ' $\leq$ ' with respect to $P$ in $E$ is defined as follows:

$$
x \leq y \quad(x<y) \quad \text { if and only if } \quad y-x \in P \quad(y-x \in P \text { and } x \neq y)
$$

for all $x, y \in E$.

Throughout this paper, let $E$ be a Banach space with the norm ' $\|\cdot\|$ ' and the partial order ' $\leq$ '. Let $F(T)=\{x \in H: T x=x\}$ denote the set of all fixed points of a mapping $T$. An order interval $[x, y]$ for all $x, y \in E$ is given by

$$
[x, y]=\{z \in E: x \leq z \leq y\}
$$

Obviously, the order interval $[x, y]$ is closed and convex. In fact, let $z_{1}, z_{2} \in[x, y]$. Then $z_{1}-x \in P, z_{2}-x \in P, y-z_{1} \in P$, and $y-z_{2} \in P$; and so, for any $t \in(0,1)$,

$$
\begin{aligned}
& t z_{1}+(1-t) z_{2}-x=t\left(z_{1}-x\right)+(1-t)\left(z_{2}-x\right) \in P, \\
& y-\left(t z_{1}+(1-t) z_{2}\right)=t\left(y-z_{1}\right)+(1-t)\left(y-z_{2}\right) \in P .
\end{aligned}
$$

Thus $t z_{1}+(1-t) z_{2} \in[x, y]$, that is, $[x, y]$ is convex. Let $\left\{z_{n}\right\} \subset[x, y]$ with $\lim _{n \rightarrow \infty} z_{n}=z$. Then, for each $n \geq 1, z_{n}-x \in P$ and $y-z_{n} \in P$, and hence we have

$$
\lim _{n \rightarrow \infty} z_{n}-x=z-x \in P, \quad \lim _{n \rightarrow \infty} y-z_{n}=y-z \in P,
$$

that is, $x \leq z \leq y$ and so $z \in[x, y]$, that is, $[x, y]$ is closed. Then the convexity of the order interval $[x, y]$ implies that

$$
x \leq t x+(1-t) y \leq y
$$

for all $x, y \in E$ with $x \leq y$.

Definition 2.1 Let $K$ be a nonempty closed and convex subset of a Banach space $E$. A mapping $T: K \rightarrow E$ is said to be:

(1) monotone [3] if $T x \leq T y$ for all $x, y \in K$ with $x \leq y$;

(2) monotone nonexpansive [3] if $T$ is monotone and

$$
\|T x-T y\| \leq\|x-y\|
$$

for all $x, y \in K$ with $x \leq y$.

A Banach space $E$ is said to be:

(1) strictly convex if $\left\|\frac{x+y}{2}\right\|<1$ for all $x, y \in E$ with $\|x\|=\|y\|=1$ and $x \neq y$;

(2) uniformly convex if, for all $\varepsilon \in(0,2]$, there exists $\delta>0$ such that $\frac{\|x+y\|}{2}<1-\delta$ for all $x, y \in E$ with $\|x\|=\|y\|=1$ and $\|x-y\| \geq \varepsilon$.

The following inequality was showed by $\mathrm{Xu}[16]$ in a uniformly convex Banach space $E$, which is known as Xu's inequality. 
Lemma 2.2 (Xu [16], Theorem 2) For any real numbers $q>1$ and $r>0$, a Banach space $E$ is uniformly convex if and only if there exists a continuous strictly increasing convex function $g:[0,+\infty) \rightarrow[0,+\infty)$ with $g(0)=0$ such that

$$
\|t x+(1-t) y\|^{q} \leq t\|x\|^{q}+(1-t)\|y\|^{q}-\omega(q, t) g(\|x-y\|)
$$

for all $x, y \in B_{r}(0)=\{x \in E ;\|x\| \leq r\}$ and $t \in[0,1]$, where $\omega(q, t)=t^{q}(1-t)+t(1-t)^{q}$. In particular, take $q=2$ and $t=\frac{1}{2}$,

$$
\left\|\frac{x+y}{2}\right\|^{2} \leq \frac{1}{2}\|x\|^{2}+\frac{1}{2}\|y\|^{2}-\frac{1}{4} g(\|x-y\|) .
$$

The following conclusion is well known.

Lemma 2.3 (Takahashi [17], Theorem 1.3.11) Let $K$ be a nonempty closed convex subset of a reflexive Banach space E. Assume that $\varphi: K \rightarrow R$ is a proper convex lower semicontinuous and coercive function. Then the function $\varphi$ attains its minimum on $K$, that is, there exists $x \in K$ such that

$$
\varphi(x)=\inf _{y \in K} \varphi(y) .
$$

\section{Main results}

\subsection{Existence of fixed points}

In this section, we prove some existence theorems of fixed points of a monotone nonexpansive mapping in a uniformly convex Banach space $(E, \leq)$.

Theorem 3.1 Let $K$ be a nonempty and closed convex subset of a uniformly convex Banach space $(E, \leq)$ and $T: K \rightarrow K$ be a monotone nonexpansive mapping. Assume that there exists $x \in K$ such that $x \leq T x$, the sequence $\left\{T^{n} x\right\}_{n=1}^{\infty}$ is bounded. Then $F(T) \neq \emptyset$ and $y^{\prime} \geq x$ for some $y^{\prime} \in F(T)$.

Proof Let $x_{1}=x$ and $x_{n+1}=T x_{n}=T^{n} x$. Then $x_{1}=x \leq T x=x_{2}$, and so,

$$
x_{2}=T x_{1}=T x \leq T x_{2}=T^{2} x=x_{3} .
$$

By analogy, we must have

$$
x=x_{1} \leq x_{2} \leq x_{3} \leq \cdots \leq x_{n} \leq x_{n+1} \leq \cdots .
$$

Let $K_{n}=\left\{z \in K: x_{n} \leq z\right\}$ for all $n \geq 1$. Clearly, for each $n \geq 1, K_{n}$ is closed convex and $y \in K_{n}$ and so $K_{n}$ is nonempty too. Let $K^{*}=\bigcap_{n=1}^{\infty} K_{n}$. Then $K^{*}$ is a nonempty closed convex subset of $K$. Since $\left\{x_{n}\right\}$ is bounded, we can define a function $\varphi: K^{*} \rightarrow[0,+\infty)$ as follows:

$$
\varphi(z)=\limsup _{n \rightarrow \infty}\left\|x_{n}-z\right\|^{2}
$$


for all $z \in K^{*}$. From Lemma 2.3, it follows that there exists $y^{*} \in K_{1}$ such that

$$
\varphi\left(y^{*}\right)=\inf _{z \in K^{*}} \varphi(z) .
$$

Now, we show $y^{*}=T y^{*}$. In fact, by the definition of $K^{*}$, we obtain

$$
x_{1} \leq x_{2} \leq x_{3} \leq \cdots \leq x_{n} \leq x_{n+1} \leq \cdots \leq y^{*}
$$

Then we have $x_{n+1}=T x_{n} \leq T y^{*}$ by the monotonicity of $T$ and hence, for each $n \geq 1, x_{n} \leq$ $T y^{*}$. So we have $T y^{*} \in K^{*}$. From the convexity of $K^{*}$, it follows that $\frac{y^{*}+T y^{*}}{2} \in K^{*}$ and so, by (3.1), we have

$$
\varphi\left(y^{*}\right) \leq \varphi\left(\frac{y^{*}+T y^{*}}{2}\right), \quad \varphi\left(y^{*}\right) \leq \varphi\left(T y^{*}\right) .
$$

On the other hand, we have

$$
\begin{aligned}
\varphi\left(T y^{*}\right) & =\limsup _{n \rightarrow \infty}\left\|x_{n+1}-T y^{*}\right\|^{2} \\
& =\limsup _{n \rightarrow \infty}\left\|T x_{n}-T y^{*}\right\|^{2} \\
& \leq \limsup _{n \rightarrow \infty}\left\|x_{n}-y^{*}\right\|^{2} \\
& =\varphi\left(y^{*}\right) .
\end{aligned}
$$

Combining (3.2) and (3.3), we have

$$
\varphi\left(T y^{*}\right)=\varphi\left(y^{*}\right) .
$$

It follows from Lemma $2.2\left(q=2\right.$ and $\left.t=\frac{1}{2}\right)$ and (3.4) that

$$
\begin{aligned}
\varphi\left(\frac{y^{*}+T y^{*}}{2}\right) & =\limsup _{n \rightarrow \infty}\left\|x_{n}-\frac{y^{*}+T y^{*}}{2}\right\|^{2} \\
& =\limsup _{n \rightarrow \infty}\left\|\frac{x_{n}-y^{*}}{2}+\frac{x_{n}-T y^{*}}{2}\right\|^{2} \\
& \leq \limsup _{n \rightarrow \infty}\left(\frac{1}{2}\left\|x_{n}-y^{*}\right\|^{2}+\frac{1}{2}\left\|x_{n}-T y^{*}\right\|^{2}-\frac{1}{4} g\left(\left\|y^{*}-T y^{*}\right\|\right)\right) \\
& \leq \frac{1}{2} \varphi\left(y^{*}\right)+\frac{1}{2} \varphi\left(T y^{*}\right)-\frac{1}{4} g\left(\left\|y^{*}-T y^{*}\right\|\right) \\
& =\varphi\left(y^{*}\right)-\frac{1}{4} g\left(\left\|y^{*}-T y^{*}\right\|\right) .
\end{aligned}
$$

Noticing (3.2), we have

$$
g\left(\left\|y^{*}-T y^{*}\right\|\right) \leq \varphi\left(y^{*}\right)-\varphi\left(\frac{y^{*}+T y^{*}}{2}\right) \leq 0
$$

and $\operatorname{so} g\left(\left\|y^{*}-T y^{*}\right\|\right)=0$. Thus we have $y^{*}=T y^{*}$ by the property of $g$. This yields the desired conclusion. This completes the proof. 
Theorem 3.2 Let $K$ be a nonempty and closed convex subset of a uniformly convex Banach space $(E, \leq)$ and $T: K \rightarrow K$ be a monotone nonexpansive mapping. Assume that there exists $x \in K$ such that $T x \leq x$, the sequence $\left\{T^{n} x\right\}_{n=1}^{\infty}$ is bounded and all $n \geq 1$. Then $F(T) \neq$ $\emptyset$ and $y^{\prime} \leq x$ for some $y^{\prime} \in F(T)$.

Proof Let $x_{1}=x, x_{n+1}=T x_{n}=T^{n} x$, and let $K_{n}=\left\{z \in K: z \leq x_{n}\right\}$ for all $n \geq 1$. Using the same proof technique of Theorem 3.1, it is easy to obtain

$$
x_{n+1} \leq x_{n}
$$

for all $n \geq 1$ and $K^{*}=\bigcap_{n=1}^{\infty} K_{n}$ is a nonempty closed convex subset of $K$. The remainder of the proof is the same as ones of Theorem 3.1 and so we omit it.

Theorem 3.3 Let E be a uniformly convex Banach space with the partial order ' $\leq$ ' with respect to closed convex cone $P$ and $T: P \rightarrow P$ be a monotone nonexpansive mapping. Assume that the sequence $\left\{T^{n} 0\right\}_{n=1}^{\infty}$ is bounded. Then $F(T) \neq \emptyset$.

Proof It follows from the definition of the partial order ' $\leq$ ' that $0 \leq T 0$. Then the conclusions directly follow from Theorem 3.1.

Denote $\mathbb{R}^{m}=\left\{\left(r_{1}, r_{2}, \ldots, r_{m}\right): r_{i} \in \mathbb{R}, i=1,2, \ldots, m\right\}$ and $\mathbb{R}_{+}^{m}=\left\{\left(r_{1}, r_{2}, \ldots, r_{m}\right): r_{i} \geq 0, i=\right.$ $1,2, \ldots, m\}$, where $\mathbb{R}$ is the set of all real numbers.

Theorem 3.4 Let $T: \mathbb{R}_{+}^{m} \rightarrow \mathbb{R}_{+}^{m}$ be a monotone nonexpansive mapping. Assume that the sequence $\left\{T^{n} 0\right\}_{n=1}^{\infty}$ is bounded. Then $F(T) \neq \emptyset$.

Proof Let $T^{n} 0=\left(r_{1}^{(n)}, r_{2}^{(n)}, \ldots, r_{m}^{(n)}\right) \in \mathbb{R}_{+}^{m}$. It follows from the boundedness of the sequence $\left\{T^{n} 0\right\}$ that there exist a positive real number $r$ such that $r_{i}^{(n)} \leq r$ for all $n$ and $i=1,2, \ldots, m$. Take $y=(r, r, \ldots, r)$. So the conclusions directly follow from Theorem 3.3.

Theorem 3.5 Let $K$ be a nonempty and closed convex subset of a Banach space $(E, \leq)$ and $T: K \rightarrow K$ be a monotone nonexpansive mapping. Assume that $F(T) \neq \emptyset$ and there exist $x \in K$ and $p \in F(T)$ such that $p \leq x$ (or $x \leq p$ ). Then the sequence $\left\{T^{n} x\right\}$ is bounded.

Proof Let $x_{1}=x$ and $x_{n+1}=T x_{n}=T^{n} x$. Then it follows from the conditions $p=T p$ and $p \leq x($ or $x \leq p)$ that $p=T p \leq T x_{n}=x_{n+1}$ (or $\left.x_{n+1}=T x_{n} \leq T p=p\right)$ for all $n \geq 1$ and so

$$
\begin{aligned}
& \left\|x_{2}-p\right\|=\left\|T x_{1}-T p\right\| \leq\left\|x_{1}-p\right\|=\|x-p\|, \\
& \left\|x_{3}-p\right\|=\left\|T x_{2}-T p\right\| \leq\left\|x_{2}-p\right\| \leq\|x-p\|, \\
& \ldots, \\
& \left\|x_{n}-p\right\|=\left\|T x_{n-1}-T p\right\| \leq\left\|x_{n-1}-p\right\| \leq\|x-p\|, \\
& \left\|x_{n+1}-p\right\|=\left\|T x_{n}-T p\right\| \leq\left\|x_{n}-p\right\| \leq\|x-p\|,
\end{aligned}
$$

and so $\left\|x_{n}-p\right\| \leq\|x-p\|$ for all $n \geq 1$ and hence the sequence $\left\{T^{n} x\right\}$ is bounded. This completes the proof. 
Theorem 3.6 Let $E$ be a Banach space with the partial order ' $\leq$ ' with respect to closed convex cone $P$ and $T: P \rightarrow$ P be a monotone nonexpansive mapping. Assume that $F(T) \neq \emptyset$. Then the sequence $\left\{T^{n} 0\right\}$ is bounded. Furthermore, the sequence $\left\{T^{n} x\right\}$ is bounded for all $x \in P$.

Proof It follows from the definition of $T$ that $0 \leq p$ for all $p \in F(T)$. Then the conclusion that $\left\{T^{n} 0\right\}$ is bounded directly follows from Theorem 3.5. For each $x \in P$, it is obvious that $0 \leq x$ and hence, by the monotonicity of $T$, we have

$$
T 0 \leq T x, T^{2} 0 \leq T^{2} x, \ldots, T^{n} 0 \leq T^{n} x, \ldots
$$

It follows from the definition of a monotone nonexpansive mapping that

$$
\begin{aligned}
& \|T x-T 0\| \leq\|x-0\|=\|x\|, \\
& \left\|T^{2} x-T^{2} 0\right\| \leq\|T x-T 0\| \leq\|x\|, \\
& \ldots, \\
& \left\|T^{n} x-T^{n} 0\right\| \leq\left\|T^{n-1} x-T^{n-1} 0\right\| \leq\|x\|, \\
& \left\|T^{n+1} x-T^{n+1} 0\right\| \leq\left\|T^{n} x-T^{n} 0\right\| \leq\|x\|,
\end{aligned}
$$

and so the sequence $\left\{T^{n} x\right\}$ is bounded. The desired conclusion follows. This completes the proof.

Theorem 3.7 Let $T: \mathbb{R}_{+}^{m} \rightarrow \mathbb{R}_{+}^{m}$ be a monotone nonexpansive mapping. Then $F(T) \neq \emptyset$ if and only if the sequence $\left\{T^{n} 0\right\}$ is bounded.

Proof The conclusions directly follow from Theorems 3.4 and 3.6.

\subsection{The convergence of the Mann iteration}

In this section, for a monotone nonexpansive mapping $T$, we consider the Mann iteration sequence defined by

$$
x_{n+1}=\beta_{n} x_{n}+\left(1-\beta_{n}\right) T x_{n}
$$

for each $n \geq 1$, where $\left\{\beta_{n}\right\}$ in $(0,1)$ satisfies the following condition:

$$
\sum_{n=1}^{\infty} \beta_{n}\left(1-\beta_{n}\right)=\infty .
$$

Clearly, the above condition contains $\beta_{n}=\frac{1}{n+1}$ as a special case.

The following lemma is showed by Dehaish and Khamsi [15], where the conclusion (3) is obtained from the proof of Lemma 3.1 in [15].

Lemma 3.8 (Dehaish and Khamsi [15], Lemmas 3.1 and 3.2) Let $K$ be a nonempty and closed convex subset of a Banach space $(E, \leq)$ and $T: K \rightarrow K$ be a monotone nonexpansive 
mapping. Assume that the sequence $\left\{x_{n}\right\}$ is defined by (3.5) and $x_{1} \leq T x_{1}$ (or $\left.T x_{1} \leq x_{1}\right)$. If $F(T) \neq \emptyset$ and $p \leq x_{1}$ (or $x_{1} \leq p$ ) for some $p \in F(T)$, then

(1) $\left\{x_{n}\right\}$ is bounded and $x_{n} \leq x_{n+1} \leq T x_{n}$ (or $\left.T x_{n} \leq x_{n+1} \leq x_{n}\right)$;

(2) $\lim _{n \rightarrow \infty}\left\|x_{n}-p\right\|$ exists;

(3) $x_{n} \leq x$ (or $\left.x \leq x_{n}\right)$ for all $n \geq 1$ provided $\left\{x_{n}\right\}$ weakly converges to a point $x \in K$.

Theorem 3.9 Let $K$ be a nonempty and closed convex subset of a uniformly convex Banach space $(E, \leq)$ and $T: K \rightarrow K$ be a monotone nonexpansive mapping. Assume that the sequence $\left\{x_{n}\right\}$ is defined by (3.5) and $x_{1} \leq T x_{1}$ (or $\left.T x_{1} \leq x_{1}\right)$. If $F(T) \neq \emptyset$ and $p \leq x_{1}$ (or $\left.x_{1} \leq p\right)$ for some $p \in F(T)$, then

$$
\lim _{n \rightarrow \infty}\left\|x_{n}-T x_{n}\right\|=0
$$

Proof It follows from Lemma 3.8 that

$$
p \leq x_{1} \leq x_{n} \quad\left(\text { or } x_{n} \leq x_{1} \leq p\right)
$$

for all $n \geq 1$. Then it follows from the nonexpansiveness of $T, p=T p$, and an application of Lemma $2.2\left(q=2\right.$ and $\left.t=\beta_{n}\right)$ that

$$
\begin{aligned}
\left\|x_{n+1}-p\right\|^{2} & =\left\|\beta_{n}\left(x_{n}-p\right)+\left(1-\beta_{n}\right)\left(T x_{n}-T p\right)\right\|^{2} \\
& \leq \beta_{n}\left\|x_{n}-p\right\|^{2}+\left(1-\beta_{n}\right)\left\|T x_{n}-T p\right\|^{2}-\beta_{n}\left(1-\beta_{n}\right) g\left(\left\|x_{n}-T x_{n}\right\|\right) \\
& \leq\left\|x_{n}-p\right\|^{2}-\beta_{n}\left(1-\beta_{n}\right) g\left(\left\|x_{n}-T x_{n}\right\|\right),
\end{aligned}
$$

and so

$$
\beta_{n}\left(1-\beta_{n}\right) g\left(\left\|x_{n}-T x_{n}\right\|\right) \leq\left\|x_{n}-p\right\|^{2}-\left\|x_{n+1}-p\right\|^{2} .
$$

Therefore, we have

$$
\sum_{n=1}^{\infty} \beta_{n}\left(1-\beta_{n}\right) g\left(\left\|x_{n}-T x_{n}\right\|\right) \leq\left\|x_{1}-p\right\|^{2}<+\infty
$$

Now, we claim that there exists a subsequence $\left\{x_{n_{k}}\right\}$ such that

$$
\lim _{k \rightarrow \infty} g\left(\left\|x_{n_{k}}-T x_{n_{k}}\right\|\right)=0 .
$$

Suppose that the conclusion is not true. Then, for all subsequences $\left\{x_{n_{k}}\right\}$ such that $\lim _{k \rightarrow \infty} g\left(\left\|x_{n_{k}}-T x_{n_{k}}\right\|\right)>0$, we have

$$
\liminf _{n \rightarrow \infty} g\left(\left\|x_{n}-T x_{n}\right\|\right)>0 .
$$

Thus there exists a positive number $a$ and a positive integer $N$ such that $g\left(\left\|x_{n}-T x_{n}\right\|\right)>$ $a>0$ for all $n>N$. Consequently, we have

$$
\beta_{n}\left(1-\beta_{n}\right) g\left(\left\|x_{n}-T x_{n}\right\|\right) \geq a \beta_{n}\left(1-\beta_{n}\right)
$$


and hence, by the condition $\sum_{n=1}^{\infty} \beta_{n}\left(1-\beta_{n}\right)=+\infty$, we obtain

$$
\sum_{n=1}^{\infty} \beta_{n}\left(1-\beta_{n}\right) g\left(\left\|x_{n}-T x_{n}\right\|\right)=+\infty
$$

This contradicts (3.6). So (3.7) holds and hence, by the property of $g$, we have

$$
\lim _{k \rightarrow \infty}\left\|x_{n_{k}}-T x_{n_{k}}\right\|=0
$$

On the other hand, we have

$$
\begin{aligned}
\left\|x_{n+1}-T x_{n+1}\right\| & =\left\|\beta_{n}\left(x_{n}-T x_{n}\right)+\left(T x_{n}-T x_{n+1}\right)\right\| \\
& \leq \beta_{n}\left\|x_{n}-T x_{n}\right\|+\left\|x_{n+1}-x_{n}\right\| \\
& =\beta_{n}\left\|x_{n}-x_{n}-T x_{n}\right\|+\left(1-\beta_{n}\right)\left\|x_{n}-T x_{n}\right\| \\
& =\left\|x_{n}-T x_{n}\right\| .
\end{aligned}
$$

Therefore, the sequence $\left\{\left\|x_{n}-T x_{n}\right\|\right\}$ is monotonically non-increasing and hence it follows that $\lim _{n \rightarrow \infty}\left\|x_{n}-T x_{n}\right\|$ exists. This yields the desired conclusion. This completes the proof.

Recall that a Banach space $E$ is said to satisfy Opial's condition [12] if a sequence $\left\{x_{n}\right\}$ with $\left\{x_{n}\right\}$ weakly converges to a point $x \in E$ implies

$$
\limsup _{n \rightarrow \infty}\left\|x_{n}-x\right\|<\limsup _{n \rightarrow \infty}\left\|x_{n}-y\right\|
$$

for all $y \in E$ with $y \neq x$.

Next, we show the weak convergence of the sequence $\left\{x_{n}\right\}$ defined by (3.5). The proof is similar to the ones of Dehaish and Khamsi [15], but, for more details, we give the proof.

Theorem 3.10 Let $K$ be a nonempty and closed convex subset of a uniformly convex Banach space $(E, \leq)$ and $T: K \rightarrow K$ be a monotone nonexpansive mapping. Assume that $E$ satisfies Opial's condition and the sequence $\left\{x_{n}\right\}$ is defined by (3.5) with $x_{1} \leq T x_{1}$ (or $T x_{1} \leq x_{1}$ ). If $F(T) \neq \emptyset$ and $p \leq x_{1}$ (or $x_{1} \leq p$ ) for some $p \in F(T)$, then $\left\{x_{n}\right\}$ weakly converges to a fixed point $x^{*}$ of $T$.

Proof It follows from Lemma 3.8 and Theorem 3.9 that $\left\{x_{n}\right\}$ is bounded and

$$
\lim _{n \rightarrow \infty}\left\|x_{n}-T x_{n}\right\|=0
$$

Then there exists a subsequence $\left\{x_{n_{k}}\right\} \subset\left\{x_{n}\right\}$ such that $\left\{x_{n_{k}}\right\}$ weakly converges to a point $x^{*} \in K$. Following Lemma 3.8, we have $x_{1} \leq x_{n_{k}} \leq x^{*}$ (or $x^{*} \leq x_{n_{k}} \leq x_{1}$ ) for all $k \geq 1$. In particular, we have

$$
\lim _{k \rightarrow \infty}\left\|x_{n_{k}}-T x_{n_{k}}\right\|=0
$$


Now, we claim $x^{*}=T x^{*}$. In fact, suppose that this is not true. Then, from the nonexpansiveness of $T$ and Opial's condition, it follows that

$$
\begin{aligned}
\limsup _{k \rightarrow \infty}\left\|x_{n_{k}}-x^{*}\right\| & <\limsup _{k \rightarrow \infty}\left\|x_{n_{k}}-T x^{*}\right\| \\
& \leq \limsup _{k \rightarrow \infty}\left(\left\|x_{n_{k}}-T x_{n_{k}}\right\|+\left\|T x_{n_{k}}-T x^{*}\right\|\right) \\
& \leq \limsup _{k \rightarrow \infty}\left\|x_{n_{k}}-x^{*}\right\|,
\end{aligned}
$$

which is a contradiction. Thus, by Lemma 3.8(2), it follows that the $\operatorname{limit}_{\lim } \rightarrow \infty\left\|x_{n}-x^{*}\right\|$ exists.

Now, we show that $\left\{x_{n}\right\}$ weakly converges to the point $x^{*}$. Suppose that this is not true. Then there exists a subsequence $\left\{x_{n_{j}}\right\}$ that converges weakly to a point $z \in K$ and $z \neq x^{*}$. Similarly, it follows that $z=T z$ and $\lim _{n \rightarrow \infty}\left\|x_{n}-z\right\|$ exists. It follows from Opial's condition that

$$
\lim _{n \rightarrow \infty}\left\|x_{n}-z\right\|<\lim _{n \rightarrow \infty}\left\|x_{n}-x^{*}\right\|=\limsup _{i \rightarrow \infty}\left\|x_{n_{i}}-x^{*}\right\|<\lim _{n \rightarrow \infty}\left\|x_{n}-z\right\| .
$$

This is a contradiction and hence $x^{*}=z$. This completes the proof.

\section{Competing interests}

The authors declare that they have no competing interests.

\section{Authors' contributions}

All authors contributed equally and significantly in writing this article. All authors read and approved final manuscript.

\section{Author details}

'Henan Engineering Laboratory for Big Data Statistical Analysis and Optimal Control, School of Mathematics and Information Science, Henan Normal University, Xinxiang, Henan 453007, P.R. China. ${ }^{2}$ Department of Mathematics, King Mongkut's University of Technology Thonburi, 120 Pracha-Uthnit Road, Bang Mod, Thung Khru, Bangkok, 10140, Thailand. ${ }^{3}$ Department of Mathematics Education and the RINS, Gyeongsang National University, Jinju, 660-701, Korea.

\section{Acknowledgements}

The work was supported by the Higher Education Research Promotion and National Research University Project of Thailand, Office of the Higher Education Commission (NRU59 Grant No. 59000399). Also, the work was supported by the National Natural Science Foundation of P.R. China (Grant No. 11571095), Program for Innovative Research Team (in Science and Technology) in University of Henan Province (14IRTSTHN023). Yeol Je Cho was supported by Basic Science Research Program through the National Research Foundation of Korea (NRF) funded by the Ministry of Science, ICT and future Planning (2014R1A2A2A01002100). Moreover, this work was carried out while Yeol Je Cho was visiting Theoretical and Computational Science Center (TaCS), Science Laboratory Building, Faculty of Science, King Mongkut's University of Technology Thonburi (KMUTT), Bangkok, Thailand, during 15 January-3 March 2016. He thanks Professor Poom Kumam and the university for their hospitality and support.

Received: 13 January 2016 Accepted: 17 June 2016 Published online: 29 June 2016

\section{References}

1. Aoyama, K, lemoto, S, Kohsaka, F, Takahashi, W: Fixed point and ergodic theorems for $\lambda$-hybrid mappings in Hilbert spaces. J. Nonlinear Convex Anal. 11, 335-343 (2010)

2. Aoyama, K, Kohsaka, F: Fixed point theorem for $\alpha$-nonexpansive mappings in Banach spaces. Nonlinear Anal. 74, 4387-4391 (2011)

3. Bachar, M, Khamsi, MA: On common approximate fixed points of monotone nonexpansive semigroups in Banach spaces. Fixed Point Theory Appl. 2015, 160 (2015)

4. Mann, WR: Mean value methods in iteration. Proc. Am. Math. Soc. 4, 506-510 (1953)

5. Jung, JS: Iterative approaches to common fixed points of nonexpansive mappings in Banach spaces. J. Math. Anal. Appl. 302, 509-520 (2005)

6. Liu, LS: Ishikawa and Mann iteration process with errors for nonlinear strongly accretive mappings in Banach spaces. J. Math. Anal. Appl. 194, 114-125 (1995)

7. Suzuki, T: Strong convergence of Krasnoselskii and Mann's sequences for one-parameter nonexpansive semigroups without Bochner integrals. J. Math. Anal. Appl. 305, 227-239 (2005) 
8. Song, Y, Huang, Y: Fixed point property and approximation of a class of nonexpansive mappings. Fixed Point Theory Appl. 2014, 81 (2014)

9. Song, $Y$, Wang, $H$ : Strong convergence for the modified Mann's iteration of $\lambda$-strict pseudocontraction. Appl. Math. Comput. 237, 405-410 (2014)

10. Song, Y: Weak and strong convergence of Mann's-type iterations for a countable family of nonexpansive mappings. J. Korean Math. Soc. 45, 1393-1404 (2008)

11. Song, $\mathrm{Y}, \mathrm{Xu}, \mathrm{S}$ : Strong convergence theorems for nonexpansive semigroup in Banach spaces. J. Math. Anal. Appl. 338, 152-161 (2008)

12. Opial, Z: Weak convergence of the sequence of successive approximations for nonexpansive mappings in Banach spaces. Bull. Am. Math. Soc. 73, 591-597 (1967)

13. Zhou, $\mathrm{H}$ : Convergence theorems for $\boldsymbol{\lambda}$-strict pseudo-contractions in 2-uniformly smooth Banach spaces. Nonlinear Anal. 69, 3160-3173 (2008)

14. Zhang, H, Su, Y: Convergence theorems for strict pseudo-contractions in q-uniformly smooth Banach spaces. Nonlinear Anal. 71, 4572-4580 (2009)

15. Dehaish, BAB, Khamsi, MA: Mann iteration process for monotone nonexpansive mappings. Fixed Point Theory Appl. 2015, 177 (2015)

16. Xu, HK: Inequality in Banach spaces with applications. Nonlinear Anal. 16, 1127-1138 (1991)

17. Takahashi, W: Nonlinear Functional Analysis-Fixed Point Theory and Its Applications. Yokohama Publishers, Yokohama (2000)

\section{Submit your manuscript to a SpringerOpen ${ }^{\circ}$ journal and benefit from:}

- Convenient online submission

- Rigorous peer review

- Immediate publication on acceptance

- Open access: articles freely available online

- High visibility within the field

- Retaining the copyright to your article 